\title{
Da cidadania à realização de projetos de vida: inclusão social de usuários de um Centro de Atenção Psicossocial na vida cotidiana
}

| ${ }^{1}$ Mariana Moraes Salles, ${ }^{2}$ Sonia Barros |

Resumo: Os objetivos do presente artigo foram identificar e analisar as possibilidades e dificuldades de usuários de um Centro de Atenção Psicossocial (CAPS) em relação à cidadania e à construção de projetos de vida na perspectiva da promoção da inclusão social. Utilizou-se a abordagem qualitativa como metodologia de pesquisa e a teoria sobre o cotidiano de Agnes Heller como referencial filosófico. Para a coleta de dados foram realizadas entrevistas semiestruturadas com usuários e pessoas da sua rede social. Para apuração dos dados foi utilizada a Análise do Discurso. Os usuários encontram dificuldades para ter os seus direitos garantidos, porém também encontram possibilidades, principalmente com a ajuda do CAPS. Além disso, eles lutam por seus direitos engajando-se nos movimentos sociais, promovendo seus próprios processos de inclusão. O exercício da cidadania é o primeiro passo em direção à inclusão social. Os próximos passos são trilhados a partir dos desejos e projetos pessoais de cada usuário, em articulação com as possibilidades oferecidas pelo contexto.

> Palavras-chave: Saúde Mental; Assistência em Saúde Mental; Mudança Social; Justiça Social; Participação Social.
1 Doutora em Cuidado em Saúde, Escola de Enfermagem da Universidade de São Paulo. Pós-doutoranda, Universidade Federal de São Carlos. São Carlos-SP, Brasil. Endereço eletrônico: marianamsalles@ gmail.com.

2 Professor titular,

Departamento de Enfermagem Materno-Infantil e Psiquiátrica, Escola de Enfermagem da Universidade de São Paulo. São Carlos-SP, Brasil. Endereço eletrônico: sobarros@ups.br.

Recebido em: 06/05/2014 Aprovado em: 01/09/2014 
Atualmente, na atenção à saúde mental, a questão da inclusão social das pessoas com transtornos mentais está sendo cada vez mais discutida. Dois dos eixos centrais desse debate nesse debate são as possibilidades de realização dos projetos de vida dos sujeitos e o exercício da cidadania.

Ser cidadão significa ter direitos e deveres. Na proposição da cidadania, todos os homens são iguais perante a lei e cabe a todos o domínio sobre o seu corpo e sua vida, o acesso a um salário, o direito a educação, saúde, habitação e lazer, o direito de expressar-se livremente e o de participar de movimentos sociais; enfim, todos têm o direito de ter uma vida digna como ser humano (CERQUIER-MANZINI, 2010).

É preciso que se assimile efetivamente o significado de direitos humanos, exigindo cidadania integral e dignidade para todos, seja legalmente, seja no cotidiano. A cidadania é considerada um direito para todos, não apenas para os iguais, mas, sobretudo, para os diferentes (CHAMMA; FORCELLA, 2002). Todas as pessoas deveriam ser respeitadas, sem sofrer discriminação ou exclusão devido à raça, cor, credo, ou diagnóstico médico.

Entretanto, uma série de direitos políticos e pessoais disponíveis para todos os cidadãos podem ser retirados da pessoa com transtorno mental. Com base no argumento de que são legalmente incapazes, eles podem, por exemplo, perder o direito de manejar seus bens, assinar contratos, casar ou perder a guarda dos filhos (THORNICROFT, 2006).

Como efeito da discriminação, as pessoas com transtornos mentais sofrem algum nível de exclusão e privação de seus direitos, mesmo quando vivem na comunidade, encontrando seu lugar social junto com outros grupos excluídos socialmente (MEZZINA et al., 2006). Nesse sentido, a inclusão social de pessoas com transtornos mentais implica o exercício da cidadania e a participação no mercado de trabalho e no contexto social. Assim, a atenção aos usuários em saúde mental pressupõe que eles possam usufruir seus direitos básicos, como liberdade, moradia e trabalho (LEÃO; BARROS, 2011).

Contudo, o processo de inclusão social não se resume ao direito à cidadania e ao trabalho. A cidadania coloca o sujeito em condições mínimas de inclusão social, porém são os projetos de vida de cada usuário que mostram um caminho 
a ser seguido no processo de inclusão de cada um. Nesse sentido, é preciso estar

atento aos desejos e necessidades individuais dos usuários e ajudá-los a viver a partir de suas singularidades no contexto social no qual estão inseridos.

No cuidado com a saúde, é preciso buscar a totalidade existencial que permita dar significado e sentido não apenas à saúde, mas ao próprio projeto de vida. Esse projeto ressignifica tudo à volta do sujeito, inclusive, e especialmente, o cuidado de si (AYRES, 2004).

$\mathrm{O}$ atual momento de transformação da assistência em saúde mental nos leva a questionar sobre como se dá o exercício da cidadania dos usuários e sobre as possibilidades deles realizarem seus projetos de vida, tendo em vista os processos de inclusão/exclusão social que ocorrem na vida cotidiana. Assim, os objetivos do presente artigo $^{1}$ foram identificar e analisar as possibilidades e dificuldades de usuários de um Centro de Atenção Psicossocial (CAPS) em relação ao exercício da cidadania e à construção de seus projetos de vida, na perspectiva da promoção da inclusão social.

\section{Metodologia}

O estudo utilizou metodologia de pesquisa qualitativa. Para oferecer embasamento teórico para seu desenvolvimento, foi utilizada como referencial filosófico a teoria sobre o cotidiano, de Agnes Heller. Segundo Heller (2000), todo homem vive a vida cotidiana, com suas capacidades, habilidades, sentimentos, paixóes, ideias e ideologias. O coletivo está contido em todo homem. O homem individual é, ao mesmo tempo, um ser genérico, já que é produto de suas relações sociais, sucessor e preservador do desenvolvimento humano; não é sozinho, mas está sempre em integração com outros homens.

Para a pessoa em sofrimento psíquico, sua história individual está em articulação com a de outras pessoas que tiveram transtorno mental e encontraram dificuldades em sua inclusão, e também em articulação com o contexto de iniciativas voltadas para a transformação na atenção em saúde mental e a construção de novas formas de se relacionar com o doente mental.

A vida cotidiana dos homens proporciona, em termos gerais, a imagem de como se reproduz a sociedade na qual esse indivíduo vive (HELLER, 2002). Assim, ao analisar a vida cotidiana dos sujeitos entrevistados, há também uma referência à forma da sociedade se organizar e reproduzir. 
Os sujeitos desta investigação foram pessoas com transtorno psíquico, usuários de um CAPS II na região oeste de São Paulo, codificados com a letra U. Foi solicitado ao diretor do serviço que identificasse ações do CAPS que têm como objetivo promover a inclusão social. Foram indicadas quatro oficinas com esse objetivo: a oficina Recicla Tudo, a oficina de panificação, o Brechó e o grupo Criativa. Também foram entrevistadas pessoas indicadas pelos usuários, codificadas com a letra $\mathrm{R}$ (pessoa da rede social do usuário), por serem significativas na inclusão social do sujeito com transtorno mental. Foram realizadas, no total, 29 entrevistas, 17 com usuários e 12 com pessoas de sua rede de relações sociais.

O Comitê de Ética e Pesquisa da Secretaria Municipal de Saúde autorizou o desenvolvimento desta pesquisa (Parecer $n^{\circ}$ 143/08). Os entrevistados assinaram um termo de consentimento livre e esclarecido (TCLE), permitindo a utilização dos dados coletados, e foi garantido sigilo sobre a identidade dos entrevistados.

Para a coleta de dados foram realizadas entrevistas semiestruturadas. Para análise dos dados foi utilizada a Análise do Discurso, que considera que os discursos devem ser pensados a partir dos processos históricos e sociais que os constituem. O lugar histórico-social em que se encontram os sujeitos enunciadores de determinado discurso envolve o contexto e a situação que intervêm na produção do discurso.

A Análise do Discurso não trata da língua ou da gramática. Embora esses assuntos lhe interessem, ela trata do discurso, isto é, a palavra em movimento; a partir do exame do discurso, observa-se o homem falando (ORLANDI, 2007).

Para toda fala, sempre há um sujeito que diz, pronuncia as palavras; um sujeito com uma história pessoal, que pensa, se relaciona e vive em um determinado contexto social. O sujeito que fala é um sujeito histórico-social que, quando fala, procura compreender o mundo, produzir sentidos e expressar sua forma de ser e viver. Assim, compreendem-se os entrevistados como sujeitos históricos e seus discursos como inseridos em um determinado momento histórico do processo da Reforma Psiquiátrica.

Neste trabalho, após a coleta de dados, as entrevistas foram transcritas, constituindo um texto para análise. Após a transcrição e diversas leituras das entrevistas, o texto foi organizado em frases temáticas arranjadas segundo suas afinidades. 
Após essa etapa, o texto foi revisto, com vistas a encontrar conexão entre

os temas, para então se definirem as categorias empíricas inerentes ao discurso. Foram identificadas as seguintes categorias empíricas: "processo de exclusão/ inclusão social”, "redes sociais", e "cuidado em saúde mental”. Após a definição das categorias empíricas, foi realizada uma análise reflexiva sobre os dados, em diálogo com a literatura. O presente artigo trata da categoria empírica "processo de exclusão/inclusão social".

\section{Resultados e discussão}

\section{A cidadania como requisito básico para inclusão social}

Os entrevistados relataram que a participação na sociedade, como cidadão, é uma forma de inclusão social. Para o sujeito historicamente tratado como não cidadão, esse é um avanço em sua inclusão social. A cidadania é um conceitochave para a noção de inclusão social. Para alcançá-la, é preciso convencer o sistema legal a incluir direitos e oportunidades para as pessoas com transtornos mentais, para que elas tenham acesso a trabalho, moradia, participação em programas educacionais e o direito ao voto. Isso requer uma visão que vá além do paradigma médico, que tem os sintomas como principal foco de intervenção (LLOYD et al., 2006).

Eu sou incluído porque sou um cidadão brasileiro, só isso... (U3)

Eu acho que eles merecem o atendimento e o respeito; o reconhecimento de que eles, assim como nós, são seres humanos que estão enfrentando uma dificuldade. Eu acho que todos são dignos de acolhimento, de atenção e cuidado, como qualquer ser humano precisa ter. (R13)

O movimento de usuários em saúde mental tem dado grande importância aos direitos sociais básicos e especiais, dado o contexto mais amplo de pobreza (VASCONCELOS, 2000). Muitos dos usuários necessitam do auxílio de serviços de assistência social ou do CAPS para garantir sua sobrevivência. Em uma sociedade em que os direitos sociais não são garantidos para todos, o acesso a condições mínimas de vida também é importante para a inclusão social. Assim, pode-se considerar que é possível realizar uma transformação na vida cotidiana do sujeito a partir de uma mudança na forma de organização social.

Aqui [no CAPS] nós temos alimentação também. Tem banho para quem quer tomar banho... Tem roupa... Tem um suporte bom... (U16) 
Os entrevistados da rede social dos usuários relataram que as pessoas com transtornos mentais estão em condições desfavoráveis para manter emprego e qualidade de vida e, portanto, necessitam de auxílio do governo. Esse é um reflexo da forma de produção social atual, em que não há possibilidade de trabalho para todos. Assim, a inclusão social também se refere a receber dinheiro suficiente para viver através de benefícios sociais (BERTRAM, 2008). Porém, existe o dilema entre reivindicar direitos especiais e lutar pelos direitos civis, contra o estigma, a discriminação e a tutela, já que a luta contra a discriminação baseia-se na igualdade entre todos. Os direitos especiais fornecidos às pessoas com transtornos mentais têm sido justificados em razão das experiências radicais por que passam os usuários e da segregação social que vivenciam (VASCONCELOS, 2000).

E têm outros assim: 'O meu filho quando não fazia esse tratamento ou quando não tinha essa doença, ele trabalhava e mantinha a família’. (R9)

Agora, têm muitos que não têm nem um salário mínimo, o governo não dá uma aposentadoria, nem do mínimo, para eles se manterem. Então isso aí é preocupante. (R9)

Os entrevistados relataram ser muito importante receber auxílio financeiro devido à doença mental. Uma vez que se tornou difícil a entrada no mercado de trabalho, é essencial outra fonte de renda que garanta as condiçôes mínimas de vida. Nesse sentido, o CAPS tem oferecido apoio aos usuários para que eles tenham os direitos de assistência social garantidos, informando e auxiliando os usuários nos caminhos de acesso aos direitos sociais.

Uma maneira de os serviços de saúde mental auxiliarem os usuários no atendimento às suas necessidades é encaminhá-los para os locais de orientação em relação a benefícios e direitos sociais, ajudá-los a organizar suas finanças e realizar conexões com serviços de emprego na comunidade (POPPERWELL, 2006).

Já dei entrada no benefício. A assistente social aqui do CAPS está me ajudando. Agora estou esperando para fazer a perícia... (U16)

Eles [CAPS] se preocupam quando alguém não tem uma renda ou não tem uma aposentadoria. Eles se preocupam em correr e em conseguir. Têm muitos aqui que recebem hoje um salário, que seja, mas com ajuda do CAPS. (R9)

O direito à renda, apesar da doença e do afastamento do mercado de trabalho, seja na forma de aposentadoria por invalidez ou de auxílio-doença pela Lei Orgânica de Assistência Social, é uma forma de garantir a autonomia dos 
usuários. Sem renda, eles se tornam dependentes financeiramente dos familiares, que muitas vezes os consideram uma sobrecarga.

Os direitos sociais regulam a distribuição dos bens produzidos pela sociedade e também as formas de contato entre os homens, com base em critérios sobre o que é lícito ou ilícito (HELLER, 2002).

Graças a Deus o que ele ganha dá para ele viver. Ele recebe aposentadoria por invalidez, porque ele trabalhava como segurança, né. Se eu morrer hoje, morro tranquila, porque ele não vai depender de ninguém. (R9)

Dia 21, eu tenho entrega de documentos no INSS e depois, se eu passar na perícia, eu vou ganhar um salário mínimo. (U2)

O uso da carteira de passe livre de ônibus também é considerado um direito civil importante, que permite aos usuários ir e vir livremente, deslocando-se pela cidade com facilidade.

Como a maioria das pessoas com transtornos mentais está excluída do mercado de trabalho, elas precisam dos benefícios oferecidos pelo governo para atender suas necessidades básicas, como o direito ao transporte (THORNICROFT, 2006). Além disso, a participação em atividades que promovem a inclusão se baseia no acesso ao transporte (LLOYD et al., 2006).

Ele não fica sem aquela carteirinha. E se a carteirinha fica vencida, ele tem "siricutico". Ele cumpre as normas e ele faz o outro cumprir; ele cobra. (R16)

Porém, a assistência oferecida pelos serviços de saúde e a assistência social nem sempre são bem vistas pelos usuários, pois eles podem se sentir envergonhados por não conseguirem se sustentar sem o auxílio ou se tiverem que se submeter a morar em albergues, por exemplo. Além disso, consideram que a "verdadeira" inclusão social não é a oferecida pelo sistema de assistência social. Percebe-se nesses relatos uma censura em relação à inclusão "marginalizada" oferecida por alguns serviços de assistência social, como o albergue.

[Sobre inclusão] Não precisar de albergue, não precisar de casa de convivência, essas coisas... (U16)

Outro ponto importante é que o auxílio financeiro devido à doença vem acompanhado da premissa de que a pessoa com transtorno mental é incapaz de trabalhar ou contribuir com o sistema produtivo da sociedade. Esse fato reafirma a baixa autoestima e o estigma em relação à doença mental e coloca os usuários em uma posição passiva e de não participação. 

sistência Social] para ele, porque ele não tem capacidade laboral, de trabalhar, de se desenvolver profissionalmente. (R8)

Os usuários, porém, devem ter direito a receber auxílio do governo e escolher como viver sua vida, considerando as oportunidades do contexto. Às vezes, é importante para a pessoa com transtorno mental poder não trabalhar e receber um benefício social que a permita fazer suas próprias escolhas (MEZZINA et al., 2006).

Apesar das críticas às formas de auxílio da assistência social e saúde, alguns dos entrevistados sabem que têm direito à renda, moradia, assistência à saúde e outros, e consideram que é seu papel fazer valer esses direitos. A participação nas lutas por direitos sociais é uma forma de promover a inclusão social, e, ao mesmo tempo, fazer parte de um processo de social é a atuação ativa por uma vida melhor.

As pessoas com transtornos mentais identificam-se em sua situação de doentes e constituem associações ou organizaçōes que se estabelecem para proteger seus direitos na forma de atividade política. A luta por direitos faz parte da construção de uma nova identidade, além de ser uma maneira de acessar oportunidades reais (MEZZINA et al., 2006). A participação social pode dar a sensação de ser ouvido e respeitado em seus interesses enquanto cidadão, além de contribuir na construção de novas formas de compreender e lidar com a pobreza associada à doença mental.

Entretanto, a possibilidade de realizar encontros com prefeitos e outras autoridades não implica necessariamente uma mudança nas açōes do governo. É vital não confundir acesso com influência e não perder de vista quais estratégias são necessárias para se atingir o objetivo em questão (SAYCE, 2000).

[Sobre situação de inclusão social] Porque eu fui conselheiro da Casa Lar. Eu fui recebido na prefeitura. Recebi o crachá, fiquei dois anos lá falando com a prefeita para dar moradia para os pobres, salário mínimo para os pobres e aposentadoria para os idosos. (U7)

O lazer dele é política. Ele ia sempre na Câmara da Prefeitura, ia para todo lado, com a pastinha de baixo do braço, parecendo um doutor. Ele adora essas coisas. (R7)

Uma das formas de participação social dos usuários é tomar parte no movimento em saúde mental, uma participação específica na luta pelos direitos das pessoas com transtornos mentais. Nessas situações, os usuários são acolhidos e seu envolvimento é valorizado por todos. Essa é uma possibilidade de expressão 
dada aos sujeitos que historicamente foram excluídos e destituídos do direito à palavra, que pode se concretizar devido ao contexto da reforma psiquiátrica.

Vários encontros regionais e nacionais vêm sendo realizados pelo movimento de luta antimanicomial, que tem um papel político fundamental como força social mais avançada e autônoma do movimento de reforma psiquiátrica (VASCONCELOS, 2000). Para Mezzina et al. (2006),

[a] defesa de seus direitos torna as pessoas com transtornos mentais especialistas em
relação à sua própria experiência, possibilita que elas lutem por suas próprias neces-
sidades e também que se sintam valorizadas por ajudar outras pessoas de seu grupo.
[Sobre situação de inclusão social] Quando eu fui ao Encontro da Luta Antimani-
comial... Aí tinha familiares de todo o Brasil, usuários, familiares, os técnicos. Foi
muito bom. E eu já participei também do $1^{\circ}$ Congresso de CAPS, que foi aqui em São
Paulo. Eu recebi todo o material. Eu me senti bem... Eu falei 'Nossa, eu tô aqui.' (U9)

Outra forma de envolvimento citada foi a participação no Conselho Gestor das unidades de atendimento, que integra as questôes de saúde mental a uma rede de atenção à saúde mais ampla.

Quanto maior a participação dos usuários em diferentes instâncias de defesa por seus direitos, mais eles se sentem confiantes e capazes em diversas áreas da vida a adquirirem um papel mais ativo no seu próprio tratamento e em suas escolhas de vida (MEZZINA et al., 2006).

Eu sou membro do Conselho Gestor, que é um conselho dessa unidade, de todas as unidades de saúde. Não só o CAPS, mas as UBSs têm um Conselho Gestor. O objetivo é participar das conferências. São discutidos vários assuntos. E quando você está numa conferência, você pode aprovar medidas, aprovar novas leis de saúde mental, de saúde pública. (U9)

A concepção de cidadania pode trazer diversas vantagens: suporta a afirmação de que os direitos humanos devem ser respeitados para as pessoas com transtornos mentais; atua como ponto de referência na promoção de mudanças sociais; fixa a responsabilidade do governo, que deve responder às legitimas demandas por tratamento e se comprometer com recursos; oferece uma base que torna legítima a voz dos usuários; restringe uma resposta social baseada em pena ou benevolência; e, finalmente, assume que a dignidade é algo inato para todos (THORNICROFT, 2006). Nesse sentido, a cidadania é mais do que um status e pode ser entendida como uma prática ou um processo social (MEZZINA et al., 2006).

A luta e a conquista da cidadania fazem parte do processo de inclusão social do sujeito. Os entrevistados relataram a importância de participar da sociedade, 
ter atendidos seus direitos básicos, lutar para garanti-los, ter acesso ao trabalho e receber auxílio do governo. Esses aspectos se referem tanto à conquista da cidadania como ao processo de inclusão social.

\section{A construção da inclusão social para além dos direitos da cidadania}

Os entrevistados debatem em seus discursos sobre a garantia de seus direitos civis (respeito à liberdade individual), políticos (direito à participação social) e sociais (como direito a condições mínimas de vida). Porém, indo além de seus direitos, os usuários expressaram seus desejos e projetos pessoais, que ultrapassam a questão da cidadania e dão continuidade ao processo de inclusão social.

$\mathrm{Na}$ procura da felicidade, vivemos a vida cotidiana em transformação, com conflitos frequentes e em contínua autossuperação, fazendo algo para nós mesmos. Porém, a transformação da realidade em algo para nós implica enfrentar os conflitos do mundo, superar o presente (HELLER, 2002). Por exemplo, o direito à moradia (parte dos usuários apresenta condições precárias de habitação) não é apenas o direito de residir em local apropriado, mas também um desejo pessoal de conquistar melhores condições de moradia.

Para além dos direitos que garantem uma condição mínima de vida, a inclusão social pressupõe uma vida cotidiana com qualidade e a possibilidade de realização pessoal. Há outros aspectos moldados pelos usuários como desejos individuais, mas que também são critérios de inclusão. A inclusão social passa pela possibilidade de realização desses desejos.

Os desejos das pessoas com transtornos mentais não são diferentes dos de outras pessoas: não apenas ter onde morar, mas morar bem ou ter sua casa própria. São projetos que vão além do que os direitos se propõem a garantir, mas indicam um caminho de continuidade na construção da inclusão social. Os projetos de vida mostram uma direção no processo de inclusão social de maneira mais subjetiva.

Nesse contexto, a sensação de ter a sua própria casa é fundamental para se desenvolver o senso de uma vida cotidiana "normal” (MEZZINA et al., 2006b).

[Sobre projetos de vida] É isso: poder alugar um quarto pra mim, pra viver minha vida, não morar de favor na casa dos outros. É isso, esse é o meu projeto. (U11)

O desejo de trabalhar e ter uma boa condição financeira, sem ficar estagnado no desemprego e dependente da assistência social, foi relatado como aspecto que favorece a inclusão social. 
Pessoas com transtornos mentais dão grande importância ao trabalho.

O salário, a companhia e a rotina semanal embasam o desejo de trabalhar (GRANERUD; SEVERINSSON, 2006).

Eu tenho vontade de trabalhar, arrumar um emprego. (U2)

Eu gostaria de ter um progresso econômico, um progresso financeiro. Para comprar livros. (U15)

Quando os usuários formulam seus projetos, seus desejos se tornam mais específicos, saindo da generalidade do desejo de ter um emprego para uma construção pessoal ligada à identidade de cada um, como cada usuário gostaria de viver a sua vida. Se os direitos são genéricos, igualando os cidadãos, os desejos e projetos são particulares, são um caminho individual de construção da inclusão social. Assim, os projetos em relação à profissão são um exemplo de como os usuários propõem um trajeto pessoal na direção da inclusão social.

Então, eu queria, assim, que eu ganhasse as coisas [kit padaria] pra mim montar um negócio pra mim trabalhar. (U6)

Eu gostaria de montar uma barraquinha, tipo um chaveiro, e fazer alguma coisa... (U13)

Eu queria gravar um CD. Esse é meu sonho, não sei se vou conseguir tornar realidade. (U3)

Há muitos cursos disponíveis, e as pessoas com transtornos mentais têm grande chance de ter sucesso de aprendizagem naqueles que escolhem (JAMES; HENDERSON, 2002). Usuários de serviços de saúde mental desejam adquirir conhecimentos e aceitar desafios, assim como querem se desenvolver por iniciativa própria (GRANERUD; SEVERINSSON, 2006). Os usuários também relataram o desejo de estudar e ir além da educação básica; eles querem se aperfeiçoar e adquirir conhecimentos nas suas áreas de escolha.

Estudar francês. Estudar francês com o objetivo de um dia ser professor de francês. Difícil, mas não é impossível, porque eu já tive contato com muitas línguas... (U4)

Eu tenho curso de informática, eu tenho o básico, eu sei alguma coisa... Mas eu estava com um projeto de fazer um curso de informática. (U9)

Além disso, houve comentários sobre o desejo de ter amigos como algo que melhora a qualidade de vida. Pessoas com transtorno mental desejam uma companhia, alguém com quem compartilhar interesses em comum, construindo relacionamentos em longo prazo (GRANERUD; SEVERINSSON, 2006). 
A construção de relações interpessoais de valor passa por escolher e ter a oportunidade de encontrar pessoas, compartilhar experiências e atividades em comum, com continuidade, reciprocidade, habilidade para construir e manter o contato e a crença de que cada pessoa tem algo a oferecer (BATES, 2002).

[Sobre o que poderia melhorar] O lado da amizade, que foram abandonadas e retomadas, se possível. Se for possível também ter amizades novas. (U4)

Porém, os usuários encontram diversas dificuldades na realização de seus projetos de vida. O primeiro obstáculo é a crença de que eles não são capazes de concluí-los. Muitas vezes, tanto os usuários quanto as pessoas de sua rede social não acreditam que seja possível construir projetos para o futuro. Como resultado de séculos de exclusão e desvalorização social da pessoa com transtorno mental, perpetua-se na vida cotidiana dos usuários a imagem de que eles são incapazes da participação social. Além disso, as pessoas com transtornos mentais podem interiorizar a imagem negativa que o público tem deles e que é largamente difundida pelos meios de comunicação (BATES, 2002).

[Sobre alcançar seus objetivos] [risos] Eu precisava nascer de novo! Não, não existe um encaixe, nem real, nem imaginário, não tem como, não há forma, não existe. É tão bloqueado que seria como se fosse um labirinto, sem saída... (U4)

Eu não acredito que ele consiga ter um projeto de vida concluído. Não acredito. Posso estar muito pessimista? Talvez? Mas se ele conseguir, para mim vai ser uma surpresa, porque não é o que eu penso não. (R4)

Essa crença de que os usuários não conseguem realizar seus projetos de vida faz parte do estigma em relação à doença mental. Nessa situação, forma-se um ciclo vicioso de preconceito e discriminação em que a sociedade estabelece que não é possível que eles realizem seus projetos de vida, acompanhando a crença de que eles não são capazes de realizar tarefas. Por isso, os usuários acabam vivenciando situações de discriminação que dificultam a realização de seus projetos. Sem oportunidades no contexto social, eles levam uma vida de exclusão, o que pode criar a imagem de que eles não têm capacidade realizar de projetos, já que não participam da sociedade. É um ciclo retroalimentado entre a vida cotidiana do sujeito e os valores e preconceitos construídos socialmente, que perpetuam a exclusão social dessa população.

Apesar dos avanços nas teorias e práticas no campo da Saúde Mental, essas ideias não foram absorvidas pela cultura ocidental, que mantém as noções de que os indivíduos com transtorno psíquico são inválidos e devem se envergonhar 
disso, e de que são culpados pela sua doença e devem ser evitados. Esses valores embasam as práticas de segregação; nesse contexto, os usuários podem ter apenas a ilusão da cidadania (SAYCE, 2002).

Pra quem tem problemas psiquiátricos como ele, eu acho complicado [realizar projetos]. Eu acho difícil, mais difícil do que é para uma outra pessoa qualquer. (R12)

Por conta das limitações que esse problema acaba impondo sobre a vida da pessoa, porque são reações, pensamentos, sentimentos que eles não têm como evitar. E isso, ao meu ver, se constitui o grande dificultador da realização desses sonhos. (R13)

Em contradição com a descrença e a situação de impossibilidade relatada pelos entrevistados, também foi descrito pelas pessoas da rede social dos usuários que, ao se transformar a ideologia de que as pessoas com transtornos mentais são incapazes de realizar seus projetos, aumentam as possibilidades de elas conquistarem o que desejam. Nesse sentido, um passo importante na construção da inclusão social está em romper o preconceito e assumir uma atitude positiva em relação às pessoas com transtornos mentais.

O mais importante nos sonhos e ambições não é o fato de eles serem plausíveis, mas a habilidade que têm de dar direção e significado às nossas tentativas de fazer o que queremos. À medida que buscamos nossos sonhos fazemos coisas, conhecemos pessoas e diferentes oportunidades se apresentam. Como resultado disso, nossas aspirações mudam, e muitas vezes mudamos de direção (PERKINS; REPPER, 2003).

Eu acho que ele tem condiçôes [de realizar projetos de vida] sim, porque eu acho que a pessoa, quando ela quer, tudo ela pode na vida. Ela pode ser doente da cabeça ou não ser... Agora, se ela não tiver vontade de viver, aí ela não consegue nada. Então, o querer é o poder. (R7)

Ele pode reconstruir a vida dele. Tudo bem, ele pode tropeçar amanhã, pode cair, ele levanta um pouco machucado, esfolado, mas ele pode. É fazer ele se perceber. Se ele não se perceber, não acreditar nele, você pode fazer o que você quiser que a coisa não flui, não vai. (R16)

É fundamental essa atitude positiva das pessoas da rede social dos usuários, que acreditam nas capacidades destes e os incentivam a buscar seus projetos de vida. Quanto mais as pessoas ao redor dos usuários observarem o seu desenvolvimento, mais facilmente passarão a acreditar que eles podem ter um futuro melhor. É importante notar que as pessoas da rede social dos usuários acreditam que são eles que devem se adequar ao ambiente em que vivem. É preciso romper o pressuposto instalado na sociedade de que o sucesso desses projetos depende 
apenas do sujeito e também buscar transformações na rede social dos usuários e na sociedade de forma ampla. É preciso enfocar alteraçōes no contexto em vez de focar apenas na responsabilidade do indivíduo com transtorno mental. Os familiares dos usuários, por exemplo, precisam de informações e discussões que os ajudem a notar a visão discriminatória neles mesmos e nos outros, para que consigam repensar e desafiar essa forma de pensar (SAYCE, 2000).

Eu acho que ele é muito ansioso, até por conta das coisas que ele gostaria de realizar. Então ele tem limitações, mas eu acho que ele, ou qualquer outra pessoa, com uma boa orientação e sendo medicado com precisão, consegue. (R8)

Através da manifestação dos talentos, dos dons que cada um tem e às vezes nem sabe que tem, das habilidades. A gente se impressiona em ver o quanto eles têm habilidades e recursos, e que precisam apenas de oportunidade, do espaço, de um estímulo para por isso para fora e ver o resultado que isso gera. Eu acredito nisso. (R13)

O CAPS é um dos locais em que é possível perceber o desenvolvimento dos usuários, suas possibilidades e perspectivas. Assim, em um ambiente favorável como esse, as pessoas com transtornos mentais começam a encontrar possibilidades de realizar projetos. A questão está em como criar outros ambientes que também sejam favoráveis ao desenvolvimento dos usuários.

As pessoas com transtornos mentais precisam de um ambiente acolhedor para superar barreiras e manter um sistema de suporte. Frequentar um serviço de saúde mental diariamente pode permitir às pessoas ser quem são, para além da doença e seus sintomas; pode ser o primeiro passo para reconstruir uma rede social de suporte e ganhar experiência prática de vida. Porém, é preciso estar atento para que essa participação social não se transforme num gueto confinado ao sistema de saúde mental (MEZZINA et al., 2006).

R9: Acho que meu filho pode realizar seus projetos, é só querer. Mas tudo que eu falar dele é CAPS. Ele realiza o que ele tem vontade aqui no CAPS, aqui no CAPS ele quer tomar a frente.

R17: Acho que projetos, só se for aqui [no CAPS]. Se aqui tiver projetos, aqui ele faz.

Antes de ajudar alguém a acessar oportunidades, é essencial compreender o que a pessoa deseja. Assim, é muito mais provável que a pessoa se engaje nas atividades e nos relacionamentos de sua escolha, significativos para ela (PERKINS; REPPER, 2003).

Segundo Heller (2000), cada um constrói para si uma hierarquia das atividades cotidianas, e é importante que cada homem possa "construir para si 
uma hierarquia consciente, ditada por sua própria personalidade, no interior da hierarquia espontânea" (p. 40). Dessa forma, o sujeito entra em relação consciente com o coletivo, levando em consideração as concepções de mundo, mas ordenando as várias e heterogêneas atividades da vida a partir de suas escolhas. Essa ordenação das atividades realizadas diariamente torna a cotidianidade uma ação moral e política.

\section{Conclusões}

Percebeu-se que as pessoas com transtornos mentais encontram dificuldades para ter garantidos seus direitos enquanto cidadãos. Eles enfrentam desafios para atender suas necessidades básicas de vida, para ter acesso ao trabalho e à renda, e vivenciam a exclusão e o estigma social. Contudo, também encontram avanços e possibilidades, principalmente com o auxílio do CAPS. Além disso, eles lutam por seus direitos e pela sua cidadania, engajando-se nos movimentos sociais, promovendo seus próprios processos de inclusão social.

O exercício da cidadania oferece possibilidades aos usuários que muitas vezes os tiram da inclusão perversa. A cidadania é o primeiro passo em direção à inclusão social; é o básico, o que todos deveriam ter em uma sociedade justa. Os próximos passos no caminho da inclusão são trilhados a partir dos desejos e projetos pessoais de cada um, em articulação com as possibilidades oferecidas pelo contexto.

Para que as pessoas com transtornos mentais consigam realizar seus projetos de vida, além de usufruir as oportunidades do contexto, é preciso que lidem com o estigma e a discriminação instaurados na sociedade, que põem essa população em uma situação de desvantagem.

O CAPS tem avançado na construção de uma sociedade que permite às pessoas com transtornos mentais vivenciar processos de inclusão, sendo um local onde essa população pode ser respeitada, estar em conexão com os outros e receber incentivos para lutar pelos seus direitos e para realizar os seus projetos de vida. Porém, o CAPS pouco consegue criar oportunidades de inclusão para essa população na comunidade, e a sociedade oferece poucas possibilidades para integrar as pessoas com transtornos mentais no cotidiano social.

A vida cotidiana se desenvolve na relação entre o particular e o coletivo. A vida cotidiana de um indivíduo está intrinsecamente ligada ao contexto social em que ele vive. E a inclusão social irá ocorrer na vida cotidiana: no nível individual, 
transformando a vida do sujeito, e, no nível coletivo, transformando leis, políticas públicas e as representações sociais sobre a loucura, por exemplo. Dessa forma, para promover a inclusão social dessa população, é preciso atuar tanto no nível individual, auxiliando-a na realização de seus projetos de vida, como no nível coletivo, tornando possível que tenham direito à cidadania.

Assim, o caminho para a inclusão social dessa população passa pela conquista dos direitos referentes à cidadania e continua a partir de um projeto de vida particular de cada usuário. A inclusão social deve ser construída não apenas pelos usuários, familiares e profissionais da saúde mental, mas por toda sociedade. ${ }^{2}$

\section{Referências}

AYRES, J.R.C.M. Cuidado, os modos de ser (do) humano e as práticas de saúde. Saúde e Sociedade. São Paulo, v. 13, n.3, p. 16-29, 2004.

BATES, P. Introduction. In: BATES, P. (Ed.). Working for inclusion: making social inclusion a reality for people with severe mental health problems. London: The Saintsbury Centre for Mental Health, 2002. p. 35-6.

BERTRAM, M. What does social inclusion means? Life in the day. Bingley, v. 12, n. 2, p. 24-27, 2008.

CERQUIER-MANZINI, M.L. O que é cidadania. São Paulo: Brasiliense, 2010. 78 p.

CHAMMA, R.C.; FORCELLA, H.T. O cidadão com transtorno psíquico: reflexões sobre os direitos humanos e os direitos do paciente. São Paulo, Revista da Escola de Enfermagem da USP, v. 35, n. 2, p. 185-190, 2001.

GRANERUD, A.; SEVERINSSON, E. The struggle for social integration in the community - the experiences of people with mental health problems. Journal of Psychiatric and Mental Health Nursing. Malden, v. 13, n. 3, p. 288-293, 2006.

HELLER, A. O cotidiano e a história. São Paulo: Paz e Terra, 2000. 121 p. Sociología de la vida cotidiana. Barcelona: Península, 2002. 687 p.

JAMES, K.; HENDERSON, J. Education. In: BATES, P. (Ed.) Working for inclusion: making social inclusion a reality for people with severe mental health problems. London: The Saintsbury Centre for Mental Health, 2002. p. 123-129.

LEÃO, A.; BARROS, S. Inclusão e exclusão social: as representaçôes sociais dos profissionais de saúde mental. Interface - Comunicação, Saúde, Educação. Botucatu, v. 15, n. 36, 2011, p. 137-152. 
LLOYD, C.; TSE, S.; DEANE, F.P. Community participation and social inclusion: How practitioners can make a difference. Australian e-Journal for the Advancement of Mental Health. Sippy Downs, v. 5, n.3, 2006, p. 185-194.

MEZZINA, R. et al. From participation to citizenship: How to regain a role, a status, and a life in the process of recovery. American Journal of Psychiatric Rehabilitation, v. 9, n.1, p. 39-61, 2006.

MEZZINA, R. et al. The social nature of recovery: discussion and implications for practice. American Journal of Psychiatric Rehabilitation, v. 9, n.1, p. 63-80, 2006 b.

MINAYO, M.C.S. O desafio do conhecimento: pesquisa qualitativa em saúde. São Paulo: Hucitec, 2004.

ORLANDI, E.P. Análise do discurso: princípios e procedimentos. Campinas: Pontes, 2007. PERKINS, R.; REPPER, J. Social Inclusion and Recovery: a model for mental health practice. London: Baillière Tindall, 2003.

POPPERWELL, I. Political or parental? Life in the day. Bingley, v. 10, n. 2, p. 17-20, 2006.

SAYCE, L. From psychiatric patient to citizen: overcoming discrimination and social exclusion. London: MacMillan Press, 2000.

THORNICROFT, G. Shunned: discrimination against people with mental illness. Oxford: Oxford University Press, 2006.

VASCONCELOS, E.M. Reinvenção da cidadania, empowerment no Campo da Saúde Mental e Estratégia Política no Movimento de Usuários. In: AMARANTE, P. (Org.). Ensaios: subjetividade, saúde mental e sociedade. Rio de Janeiro: Fiocruz, 2000. p. 169-194.

\section{Notas}

${ }^{1}$ Artigo baseado em parte da tese de doutorado de Mariana Moraes Salles, apresentada em 2011, ao Programa de Pós-Graduação em Cuidado em Saúde da Escola de Enfermagem, Universidade de São Paulo. Pesquisa financiada pelo Conselho Nacional de Desenvolvimento Científico e Tecnológico, bolsa de doutorado no país (CNPq - n. 141940/2010-7). A pesquisa também foi apoiada pelo Programa de Doutorado no País com Estágio no Exterior - PDEE, da CAPES - Coordenação de Aperfeiçoamento de Pessoal de Nível Superior (Processo no 3974-08-1; bolsa sanduíche). Não existem conflitos de interesse.

${ }^{2}$ M.M. Salles participou da concepção do projeto, análise e interpretação dos dados e redação do artigo. S. Barros participou da concepção do artigo, revisão crítica do conteúdo intelectual e aprovação da versão final a ser publicada. 


\section{Abstract}

From citizenship to the fulfillment of life

projects: social inclusion of Psychosocial Care

Center's users in everyday life

This paper aims at identifying and analyzing possibilities and difficulties of Psychosocial Care Center (CAPS) users related to citizenship and the building of life projects, in the perspective of promoting social inclusion. The qualitative approach was used as the research methodology and the Agnes Heller's concept about everyday was used as a philosophical reference. Data was gathered from semi-structured interviews with users and people from their social network. Discourse analysis was used for examining the data. The service users found difficulties to get their rights assured, however, they also found possibilities, especially with CAPS's help. Furthermore, they fight for their rights, engaging in the social movements, promoting their own inclusion processes. The practice of citizenship is the first step towards social inclusion. The next steps are taken from the service user's personal projects and desires, in connection with the possibilities offered by the context.

> Key words: mental health; mental health assistance; social change; social justice; social participation. 